\title{
OS DIFÍCEIS CAMINHOS DA ENUNCIAÇÃO: ALEJANDRA PIZARNIK
}

\author{
Graciela Ravetti \\ Tradução de Zenólia Maria de Oliveira
}

\section{Resumo}

Este trabalho é uma leitura da obra poética de Alejandra Pizarnik. poeta argentina contemporânea, guiada por idéias desenvolvidas pela teoria feminista contemporânea, explorando um campo de reflexão interdisciplinar.

\section{Resumen}

Este trabajo es una lectura de la obra poética de Alejandra Pizarnik, poeta argentina contemporánea, guiada por ideas desarrolladas por la teoria feminista contemporánea, dentro de un campo de reflexión interdisciplinario.

É de fulguração e morte a parábola rimbaudiana descrita por algumas poetas latino-americanas, tais como Alfonsina Storni, Ana Cristina César e Alejandra Pizarnik. A raiz poética de Alejandra' descende da linhagem de Rimbaud e Artaud e alimentada por um surrealismo que deve ser colocado, em sua inacabada eficácia, na árvore da poesia de Octavio Paz, Alejandra e Cortázar. Minha leitura de parte da obra de Alejandra Pizarnik, poeta argentina contemporânea, propōe-se a investigar a problemática da subjetividade em sua poesia. Inserida no esforço 
de gerar uma área do imaginário feminino no qual imagens de mulher possam atuar como modeladoras de uma nova e revolucionária consciência, nossa contribuição procura dar destaque a imagens, conceitos e retalhos de escritos como formas de desconstrução dos alicerces sobre os quais se ergue a história literária oficial para, com novos elementos, povoar o paradigma literário de figuras/imagens que permitam identificaçőes inéditas e possiveis reflexōes que recoloquem o Principio Feminino e sua evolução rumo à conscientização em seu devido lugar. Este processo não seria uma mera inversão da inversão ${ }^{2}$, como diz Balandier, referindo-se a dois aspectos interrelacionados que constituem a ordem social: o bom e o mal, a ordem e a desordem. Neste sentido o dominado, o dependente ocupa, no sistema de representaçōes coletivas tradicionais, a posição inversa e desvalorizada do dominante, do senhor. A lista de características femininas observadas por algumas culturas é gerada assim, em termos de inversão, em relação aos seus homólogos masculinos. As mulheres são, então, o mal, a perturbação; são perigosas, bruxas, feiticeiras, e impuras. Busca-se a coesão social, habitualmente, através desse processo de inversão do positivo em negativo, em especial, de dois modos. Pelo temor, o medo que gera a auto-censura que "endireita" os desvios e corrige as condutas, ou pela dramatização do sacrificio a que se submete os marcados como merecedores de castigo social intenso, com vistas à purificação coletiva. Nos periodos mais remotos da sociedade - na Idade Média - um dos principais agentes do caos social, pronto para quebrar o tênue equilibrio entre o bom e - mau è a mulher diabólica e traidora. Para restaurar a ordem torna-se imperativo destrui-las, eliminá-las. A feiticeira está associada ao mal e à impureza, à obscenidade, à sexualidade liberada de sua codificação social e, de certo modo, solta para a liberdade louca.

Em Alejandra, encontramos a emergência de experiênciaschave - mais valorizadas quanto mais regressivas - em um processo de restauração dessas fontes originárias da feminilidade, de seu eu feminino e de seu eu poético nas quais o espaço para a poesia aparece como uma arma poderosa de moldagem de um imaginário que possa servir de sustento à vida: as raizes do feminino - na terra, no espirito dionísico, no intelecto, na fantasia - e seus poderes. Esse território poético assume caracteristicas dramáticas enquanto se manifesta também como representação 
dessas leis de inversão que tem como signo privilegiado o excesso, marcado pelo movimento da hipérbole. A poesia se configura, entäo, como um ritual de onde se pode dramatizar o submergido através da memória, e encontrar novas forças para reconstituir-se. Essa restauração só pode provir do aprofundamento da uniāo mais perfeita de vida e obra, de poesia e vida e de poesia e morte. Disse Alejandra:

Aquela afirmação de Hölderin, de que 'a poesia é um jogo perigoso', tem seu equivalente real em alguns sacrificios célebres: o sofrimento de Baudelaire, o suicidio de Nerval, o silêncio precoce de Rimbaud, a misteriosa e fugaz presença de Lautrèamont, a vida $e$ a obra de Artaud... Estes poetas e outros mais tem em comum haverem anulado (ou querido anular) a distância que a sociedade obriga a estabelecer entre a poesia e a vida. ${ }^{3}$

Valemo-nos aqui da divisão em três etapas que David Lagmanovicht faz da poesia de Pizarnik. A primeira, de busca, inclui os três primeiros livros: La tierra más ajena (1955), La última inocencia (1956) e Las aventuras perdidas (1958). A segunda, de maturidade poética inclui El árbol de Diana (1962) e Los trabajos y las noches(1965). A terceira, de Extracción de la piedra de locura (1968) e El infierno musical(1971), onde se verifica também uma busca, mas agora de cunho pessoal, extra-literário. Tomamos aqui alguns aspectos relativos à segunda etapa.

Alejandra Pizarnik, desde o inicio de sua obra literária, elabora sua imagem como sujeito escritor através de uma (muitas vezes enigmática e sempre conflitiva) auto-figuração lírica. Sua poesia sedimenta-se em um processo de aniquilação da palavra e de auto-aniquilação subjetiva que privilegia uma zona vazia, de onde escrever constitui-se na tarefa de preencher com palavras o inefável - o que se sabe mas nāo se pode dizer; invocam-se palavras como uma operação do impossivel, trata-se do que não se pode fazer e do que, fatalmente, nos conduz à morte (morte que, mais que sinônimo de silêncio, o é de auto-destruição. Escrever é também um instrumento privilegiado de conhecimento, uma teoria em seu sentido original de "contemplar" ou "ver", na qual as palavras embrenham-se, perseguindo os caminhos da iluminaçāo possivel, de ver além - através e apesar dos muros do entendimento - movendo-se em um périplo cuja direçāo 
violenta a experiência, vai contra a censura dos sentidos, erigese como uma operaçāo dúbia, em que a alucinação do real exige e dá lugar a seu contrário, o intento de trazer ao plano do "real", aquilo que se percebe em outras dimensões - fantásticas, metafisicas, textuais, misticas, espirituais ou, simplesmente, mentais. Nesse território não pode mais que deixar de ser luz e a poesia passa a ser o útil, a matriz, a luneta, para tomar inteligivel um mundo que, em quase todos os niveis de experiência, apresenta-se como caótico e incompreensivel. Os dados dos sentidos são preciosos, valiosos, mas o problema da ponte que une isso à realidade oferece a constataçāo do que se reconhece com facilidade, mas não se pode dizer ou transmitir de outras maneiras. A vida - este coração misterioso apenas - é impossivel de apreender. Também as pessoas e rostos humanos aparecem de modo confuso: imagens distorcidas, deformadas, as quais é dificil amar. "Un viento débil/ lleno de rostros doblados/ que recorto en forma de objetos que amar."(A.D. p. 73)

Dentro dessa lógica tenta-se sacralizar a experiência em uma espécie de retorno às origens, desde a sintaxe primitiva e suas primeiras proposiçōes declarativas até as montagens mais arriscadas, penetrando no mais paradoxal dos jogos, o da linguagem da poesia. Apesar de a linguagem ser um bem comunitário por excelência, uma das coisas que só tem sentido em seu caráter de propriedade do grupo e de que, por outro lado, o estilo poético surge, como disse Harold Bloom, do ressecamento solitário combinado com um sentimento oceânico extraordinariamente forte, em Alejandra é claro esse jogo que combina 0 isolamento mais radical com a necessidade de expressão linguística, a experiência conjunta mais relevante. Trata-se de uma dimensão da criação, potencialmente emergente, horizonte discursivo onde se desenvolve uma subjetividade que se move entre a solidäo/ afastamento/ exilio/ esquecimento e a iluminação/recordação. Território existencial a partir da escrita estilizada, que expulsa o estranho em direçăo ao exterior para descobrir com espanto que esse exterior não existe ou não se pode alcançar.

Esse paradigma a impulsiona a escrever sobre o tempo, atendendo a vozes internas, sem pedir ajuda; é a operação narcisistica da poeta que se olha nos espelhos, defendida por máscaras ferozes e que faz sua entrada a la Lewis Carrol no universo autônomo e invertido prometido pelo espelho, aquele no qual o eu parece esperar que a morte se transforme em vida. 0 
desespero que a surpreende deriva da sensação de prisão no microcosmos que impossibilita reconhecer sua própria imagem refletida.

Fala-nos um enunciador, um sujeito poético que se manifesta através da fragmentaçäo, às vezes em duas partes, outras vezes plural, geradora de uma tensāo que alimenta e, ao mesmo tempo, destrói, assim como se aniquila o sujeito se o observamos no perimetro da obra completa: existe um eu ativo e outro passivo, que se deixa levar, arrastado por diversas forças. É o escrito de uma mulher que busca intelectual e conscientemente - se perde nas gramáticas e nos livros - e que, por "descobrir a árvore de Diana", por ter "iluminações "do que vive mais além da percepção comum, é conduzida à suspeita permanente da loucura. Há nela uma parte que se sabe eterna e perene: é a poeta, que quer escrever bem e que dedica uma considerável energia ao trabalho literário. Seu saber de mulher, parte essencial de sua natureza feminina, a desliga de estereótipos tranqüilizadores com que a sociedade quer se conduzir. O saber não é inerente a mulher porque é instrumento que dá poder e, portanto, assusta, transformando as mulheres sábias em fascinantes, ainda que em horrorosos seres. Há também seu par, a mulher sujeita à morte - à solidão, ao desejo de ser amada, à falsidade dos discursos sociais, fechada em uma cripta ou em um túmulo de altos e grossos muros. O suicídio é um ato altamente subversivo, diz Alejandra, assim como o humor, o amor e a poesia. A autodestrutividade se apresenta como forma de preencher a falta, instância básica da mulher na sociedade atual e como uma marca no sistema. O caráter destrutivo do desejo tem consequências na estrutura dos poemas e na forma material do livro, na maneira de preencher a página em branco: o sujeito lirico vai-se extinguindo também em sua substância, no tom da voz, na audibilidade - as palavras se apagam como figuras em um negativo antigo, em um processo de ressecamento, de laconismo, de brevidade. 0 caminho expressivo vai desembocando em um estreitar dos limites, reduzindo as margens, executando a "letra mínima", destacando quase exclusivamente a palavra que vai-se perfilando como o falar de Eco, deixando escondido, em algum abismo, tudo o que poderiamos chamar de conteúdo narrativo, de sintaxe elaborada. Esse tipo de experiência inefável que se localiza na base do silêncio, faz com que as palavras com que as poderiam definir sejam insuficientes e corram o risco de ser mal- 
interpretadas: esse é um dos motivos que induzem ao silêncio.

Harold Bloom fala da meta de divinização que é idealizada pelos poetas, que consiste na luta por conquistar um poder que o liberte de toda e qualquer influência mas, principalmente, da influência de uma morte esperada ou da mesma necessidade de morrer. A divinização seria, nesse sentido, ao mesmo tempo uma fúria e um projeto, oferecendo desesperadas soluçōes através de uma mágica proléptica que evitaria os perigos, incluindo a própria natureza.

Na poesia de Alejandra podemos perceber, como na obra de qualquer ser humano, a construção de modelos do que são os seres humanos e de seu esquema social, moral e espiritual, ou seja, uma visão particular do que é o mundo. É paradoxal, mas essencial, observar que a visão do mundo normalmente se constrói em função do passado e do futuro. No passado do falante da poesia de Alejandra, soa uma voz que se escuta ao longe: é a menina que convoca com sua imagem a infância perdida. A de olhos abertos, a menina que grita por dentro, debaixo das camadas de névoa. É a que ,em La última inocencia (1956), quer saber-se viva e nảo deseja falar de morte. $O$ eu poético é essa menina esquecida, enterrada, que grita a partir de sua prisão.; o tu é uma figura textual de nome Alejandra, que é observada sem compreensão pela menina clarividente; é a Alejandra que se deixa arrastar pela vida, que permite a si mesma apaixonar-se e perder o amado, que está desesperada e confusa. No futuro estão as metas, que se delineiam pela pressão constante da idéia de morte, além da convicção que todos temos de que a vida é finita. A morte é o mistério essencial com que se defronta o menino (Piaget) e todas as culturas dão-Ihe tratamento especial, por exemplo, através de ritos funerários. Não obstante, a idéia de aniquilação é quase impossivel de se conceber; imaginar a própria morte é. ao mesmo tempo, uma tentação e um pesadelo. Parte do projeto de vida de uma pessoa se faz a partir do próprio posicionamento frente ao problema que a morte determina: existe vida após a morte? A resposta a essa pergunta define as estratégias de vida.

As muralhas - zonas proibidas, muros, paredes, fronteiras - que a separam da vida são minadas pelo medo e o futuro surge das centelhas como um buraco negro de onde sequer Deus (A ti te debo o que soy/ pero no tengo mañana) pode dar uma esperança. Frente a um mundo massacrado, até a noite "sofre", as andorinhas "tremem de pavor": a natureza se subverte e passa 
a ser signo desse sofrimento de mulher. A que vive dentro de si Ihe pede para sair do "cárcere da alma". As duas figuras, a que é e a que pretende ser, afastam-se na impossibilidade do encontro. E a menina cega da alma, a pequena estátua de terror, a que diz alejandra/ alejandra/ debajo estoy yo/ alejandra. Mas no poema que dá título ao livro, "La última inocencia", parte do mistério se revela: o desejo-chave é o de partir em corpo e alma .Partir significa "deshacer-se de las miradas/piedras opresoras/ que duermen en la garganta". A viajante quer ir-se para livrar-se dos olhares; está cansada de tudo, esperando a grande morte, a doce morada para tão grande descanso. A morte chama a partir do outro lado das coisas: além da noite, como Emily Dickinson e, sobretudo, além do outro lado do espelho que promete o outro lado da moeda. O que é morte no enigmático território do espelho, será vida; o sofrimento, a solidão, a tristeza, a infelicidade e o silêncio se transformarão em seu contrário. Eis a grande tentaçāo do espelho.

A consciência de que vamos morrer nos conduz a descobrir a idéia do que é o mal e parte da construção do modelo de visão do mundo basea-se na decisāo que se tem sobre o que é o mal e a reação contra ele; em que sentido somos atraidos pelo mal rumo ao decadente, ao que está morto, sem vida.

O fazer positivo $e$ as obras proporcionam um novo paradigma "a mulher-poeta", que não reconhece a compaixão como impulso humano primordial, energia que permitiria o perdão que mitiga o impulso ao auto-castigo a que se submete a personalidade ferida, maltratada. Perdoar-se para continuar vivendo, para continuar produzindo poesia, mas teria sido necessário vencer as barreiras da solidão para confiar nos demais, deixando os deuses benevolentes agirem.

A estranheza frente às coisas do mundo e ao que os homens professam, permite à Alejandra realizar um canto que avança rumo ao delírio. Definimos delirio como a crença que se ergue sem apoio argumentativo ou sem base de dados oferecidos pela experiência. Esse delírio especifico se encaminha pelo canal da poesia que permite declarar percepções como "a melodia do anjo" ou "o discurso do vento sábio" e inventar técnicas para afastar a morte que tenta a cada noite. Essa figura angelical, recorrente nesta poesia, nāo corresponde ao estereótipo elaborado no século XIX da mulher como "anjo da casa, como entidade benéfica, apoio da familia e artífice do bem-estar familiar." Aqui se trata de uma visão 
do tipo mistico/espiritual que é, a uma só vez, figura e voz, um canto de sereia como o do vento, que induz a mulher desvelada a incursionar por outras dimensōes.

O eu se apresenta como uma entidade que habita em um plano interno (profundo), em um misterioso lugar, debaixo do que é; tão submerso que seus sinais quase não se ouvem, seus gestos não são vistos: "Yo agito pañuelos/ yo lloro/ yo oculto clavos/ yo me visto de cenizas." No emaranhado de signos, a menina perdida convoca a infância: no exilio de tempo e espaço que é o presente nos poemas, as figuras vão se encorpando. A mulher aparece ameaçada em sua integridade, correndo o risco de pulverizar-se de tanta solidão. Debaixo do pranto que se vê, há outro pranto: "tú lloras debajo de tu llanto/ tú abres el cofre de tus deseos". Lembra a meninice como um impulso de alegria selvagem que destruia o mundo: agora é só restos, uma mulher que tem medo. Perdeu seu nome, o que tinha quando era uma menina cheia de vida, "engañada por su sangre". A mulher de hoje sente que, observando com intensidade, os olhos se destroem, o objeto se desfaz ante a força pétrea das coisas "reais"; em troca, a menina da lembrança, a que ela mesma foi na infância, era forte, integra e indestrutível. Agora é seu o olhar "desde o esgoto" e com a clara dissolução do sujeito no objeto.

As palavras săo a defesa ante a ameaça de solipsismo, assim como a esperança de morrer nessa vida para nascer em outra: alguma vez voltaremos a ser. As palavras são o ủnico real, solo concreto, em um mundo onde não há verdades, onde não há certezas, A tentação é a do suicídio frente ao espelho, mapa do infinito, para reaparecer em outra vida, o cortar as próprias veias para passar ao outro lado da noite.

Diz Emily Hancock que a mulher que quiser definir-se a si mesma fora das formas do patriarcado em que vive e em que se criou não conta com mapas cognitivos de suas antecessoras, não tem à mão modelos de identidade. Debaixo da aparente liberação, forças ameaçam cercear sua feminilidade e impedir sua verdadeira realização, as leis oficialistas tentam moldar-lhe o desenvolvimento que exige renúncias. A saida é recuperar a menina que vive dentro da mulher, essa menina animosa, brincalhona e satisfeita que se move no território que faz limite com a fantasia e a realidade, que alimenta a própria criatividade.

Uma das funções da linguagem poética é a colocação em um plano privilegiado de modo invocativo-poético, que pōe em 
evidência essa energia de antecipação que caracteriza a poesia; um espirito que pode prever aquilo de que necessita: "Cuando campanas muertas me anunciaron". É o silêncio da prisioneira que percebe o mundo enojado com seu riso ou que reconhece os guardiōes do inferno, ainda que, por "flashes", se dê conta de que, por momentos, "a jaula se transforma em pássaro", seu coração continua uivando a morte, lamentando a falta de coragem para morrer.

Suas crenças metafísicas, como a de que a morte não é um final, senão uma busca de um corpo mais puro, são um freio para a sensação de ser uma particula insignificante em um universo cuja amplitude e natureza estão além da compreensão humana. As crenças metafísicas devolvem-Ihe um sentido de proporção; os axiomas que mostram suas concepçōes são, por exemplo, de que tudo continuará igual se ela não se mata: a falsidade, 0 repetitivo, o interesse e o amor nāo-verdadeiro. A morte é, então, a esperança de saltar através das grades e integrar-se às forças cósmicas.

A pessoa que tem êxito ao suicidar-se é aquela que mergulha em sua fantasia no intento de fazê-la reals. Alejandra experimenta em AD, a fundo, suas fantasias mortuárias, como quando diz:

He dado un salto de mi el alba,/he dejado mi cuerpo junto a luz y he cantado la tristeza de lo que nace.(p. 69). Salta con la camisa en llamas/ de estrella a estrella/ de sombra en sombra./Muere de muerte lejana/ la que ama al viento.( p. 72), explicar con palabras de este mundo/partió de mi barco llevándome(p. 75), alguna vez' alguna vez iré sin quedarme/ me iré como quién se va(p.85).

São basicamente duas idéias: a de que existe um "dublê" dentro de si e que vai morrer. No fundo, a idéia de que a morte a salvará das vozes internas que a angustiam; a morte levará as outras, a menina e a louca que falam no seu interior. A outra idéia é a de que a morte lhe permitirá outras vidas, outras experiências existênciais: "Mañana me vestiran con cenizas del alba,/ me llenarán la boca de flores./ Aprenderé a dormirl en la memória de un muro / en la respiración./ de un animal que sueña." (LTD p. 112). As outras vidas possiveis estão claras: desde ser outra mulher, "mais normal", que pode dormir, descansar até 
compartilhar seu ser com um muro ou um animal. Poemas como "Del otro lado,outro" e "Moradas" exploram essa idéla de que a morte conduz a "moradas", a lugares de onde, de alguma forma, se possa continuar a viver: "En la mano crispada de un muerto,/ en la memoria de un loco,/ en la tristeza de un niño,/en la mano que busca el vaso,f en el vaso inalcanzable,/en la sed de siempre."(LTD p. 113).

Em muitos casos, o narrador lírico responde a um canto misterioso que escuta e não hesita em reconhecer como um chamado dos mortos. Esse contato intimo com a morte lhe permite fazer inumeráveis poemas à sua própria morte, descrever seus sentimentos e os dos outros. Georges Bataille nos revela que a linguagem não se dá independentemente do proibido e da transgressão e que, se o objeto central da proibição é a violência (visảo erótica ou morte), podemos associar à experiência de escrever a morte a certas interpretações com que Bataille examina a pintura rupestre. A transgressão da proibição da violência (matar animais) expia-se por meio da representaçăo desse ato; podemos pensar que a figuraçăo da própria morte seria também uma forma de expiaçāo, uma maneira de acostumar-se à transgressāo em marcha, um pedido de perdäo e, ao mesmo tempo, uma expiação.

A complexidade de seus desejos, a idéia da transgressão das leís, faz com que o sujeito da enunciação poética se sinta como uma fera. A impureza a impele à morte. Como terreno para a representação da subjetividade feminina, a poesia permite à Alejandra organizar processos psíquicos subversivos a partir das identidades múltiplas do eu, que aparecem como máscaras, como uma sucessão de mitos na sua construção. O paradigma do eu na poesia de Pizarnik inscreve-se no padrāo tradicional masculino do poeta solitário em contradiçāo com o que a realidade opōe, tratando de atravessar paredes e ir além, nos caminhos do desejo. - sujeito da enunciação feminina vê-se numa situação insustentável, incapaz de identificar-se com o sujeito criador e com o poético masculino e muito distante do paradigma feminino. A mulher, quando caracterizada como simbolo da Mãe/Natureza (Northorp Frye), define-se pelo silêncio, a receptividade e a absorviçāo. Assim, o laconismo de Alejandra é um movimento que se direciona contra a escrita vista como forma de autoridade fixa, modeladora, que mostra, pōe em relevo e permite expiar a transgressão contra as leis maiores de proibição da violência e da desintegração social. Os signos alcançam uma nova dimensão. 
não-realista, construtores de uma realidade aparente, do que ainda não é. A palavra inocente surge como quem conhece a obscuridade da vida, o lado sujo.

Vemos o silêncio e o silenciamento como etapas de uma luta na busca de um falar autêntico já que, como também diz Bataille, a comunicaçāo intima nāo emprega as formas externas da linguagem e sim, ocultos resplendores análogos ao riso (os transes eróticos, a angústia sacrificial, a evocação poética...) de modo que o fazer positivo da figura enunciativa que se desenha nesta poesịa é escrever; escrever é buscar a poesia como se busca uma forma que deseja um conhecimento inascessivel, seguindo essa voz escondida que se escuta ao longe, muito longe, numa solidão que é um exilio. O fazer negativo é o gesto do silêncio total, o da destruição: o suicídio.

\section{Notas}

'Alejandra Pizarnik nasceu em Buenos Aires em 1936 e se suicidou em setembro de 1972, também em Buenos Aires.

2 BALANDIER, Georges. O poder em cena. Brasilia: Editora Universidade de Brasilia, 1982, p. 41

'PIZARNIK, Alejandra. "El verbo encamado" in: Obras Completas. Buenos Aires: Corregidor, 1993.

Nota: Todas as citações deste trabalho sāo feitas levando-se em conta esta edição. A abreviação $A D$ corresponde ao livro El árbol de Diana; LTN, à Los trabajos y las noches. Ambos fazem parte desta edição de obras completas.

4 LAGMANOVICH, David. "La poesía en Alejandra Pizarnik" in: Literatura Hispanoamericana, volume II, XVII Congresso Internacional de Literatura Iberoamericana.

B BROWE. 1989,p. 202. 